\title{
Effect of Nerve Growth Factor (NGF) on Survival of Superior Cervical Ganglion (SCG) Transplanted into the Third Ventricle in Rats
}

\author{
Hiroyuki OHTA, Masako NISHIZUKA', Yasumasa ARAI ${ }^{1}$ \\ and Hiroshi SAITO \\ Department of Chemical Pharmacology, Faculty of Pharmaceutical Sciences. \\ University of Tokyo. Tokyo 113, Japan \\ 'Department of Anatomy, School of Medicine, Juntendo University. Tokyo 113. Japan
}

Accepted January 8,1990

\begin{abstract}
Effect of short-term exposure to nerve growth factor (NGF) on neuron survival of superior cervical ganglion (SCG) transplanted into the third ventricle in rats and that on neurite outgrowth of SCG neurons in a tissue culture system were examined. Because SCG taken from 3 week-old rats exhibited a high survival rate in transplantation and they were highly sensitive to NGF in culture, they were used in the short-term NGF treatment experiment. SCG from 3 week-old rats were preincubated with NGF for $30 \mathrm{~min}$ at room temperature, and then they were cultured for 2 days or grafted for 14 days. Short-term exposure to NGF at the concentration of $10 \mathrm{~kg} / \mathrm{ml}$ enhanced the survival of transplanted SCG neurons. The same concentration of NGF enhanced neurite outgrowth of SCG neurons in culture. These results suggest that short-term NGF pretreatment could increase the efficiency of neuronal transplantation.
\end{abstract}

Neuronal transplantation techniques have been experimentally $(1,2)$ and clinically $(3-$ 5) used for improving impaired brain functions. It is worth developing substances that promote the survival of transplanted neurons. Neurotrophic factors are the candidates expected to have such an effect. Among them. nerve growth factor (NGF) is the best known substance. It enhances survival and outgrowth of peripheral sympathetic and sensory neurons (6) and central chalinergic neurons in culture (7). Moreover NGF is also effective in vivo. It can protect basal forebrain cholinergic neurons from cell death after fimbria fornix transection $(8-10)$.

In 1976. Stenevi et al. (11) reported that short-term NGF exposure before transplantation did not improve SCG neuron survival. However, the NGF dasage they employed $(100 \mathrm{BU} / \mathrm{ml})$ was relatively small. Therefore, the present study was designed to elucidate whether short-term NGF exposure is ineffective on SCG neuron survival using a wide range of NGF concentrations (100 ng-100 $\mu \mathrm{g} / \mathrm{ml})$

\section{Materials and Methods}

Determination of optimal donor age: Male Wistar rats weighing 200-300 g were housed in wire-mesh cages in a temperature-. humidity- and light-controlled room (25 \pm $1{ }^{\circ} \mathrm{C}, 55 \pm 10 \%$ and a $14 \mathrm{hr}$ light and $10 \mathrm{hr}$ dark cycle). Food and water were available ad libitum. They were castrated under a deep anesthesia; and 2 weeks later, they were deeply anesthetized with a mixture of ketamine and xylazine and served as the recipients. SCG were taken from 0 day (day of birth)-, 1, 2, 3 or 4 week-old male Wistar rats. After removal of capsules, each ganglion was divided into two pieces, and one of them was aspirated into a stainless-steel cannula (O.D.= $1.0 \mathrm{~mm}, 1 . \mathrm{D} .=0.7 \mathrm{~mm}$ for SCG of 1 day-old and O.D. $=1.2 \mathrm{~mm}, 1 . \mathrm{D} .=0.8 \mathrm{~mm}$ for the $S C G$ of the rest of the donors). The cannula was stereotaxically inserted into the third ventricle of a recipient rat according to the atlas of Paxions and Watson (12), and then SCG 
tissue was slowly pushed out into the ventricle. Fourteen days after the operation, the recipient animals were perfused transcardially with $4 \%$ paraformaldehyde dissolved in $0.1 \mathrm{M}$ phosphate buffer, $\mathrm{pH}$ 7.4. Brains were removed. trimmed to the hypothalamic area. dehydrated with graded ethanol solutions and embedded in paraffin. Paraffin sections ( 8 $\mu \mathrm{m})$ were serially cut and stained with cresylviolet.

The number of SCG neurons in the transplants was counted on a Nissl preparation under a light microscope. Abercrombie's formula (13) was employed for the correction of overcount due to split cell bodies. The volume of each graft was calculated with an image analysis apparatus (MGA-1300. Mutoh
Kohgyou, Japan).

Determination of optimal donor age in terms of NGF sensitivity in culture system: SCG was taken from 0 day (day of birth) -, 3 or 5 week-old male Wistar rats. Their capsules were removed, and each ganglion was divided into two pieces under an operating microscope. SCG was cultured in medium containing $1.10,100 \mathrm{ng} .1$ or $10 \% \mathrm{~g} / \mathrm{ml} \mathrm{NGF}$ for 24 hours on 24 well-multiplates (Falcon, U.S.A.) coated with collagen (Cell matrix, Nitta gelatin. Osaka, Japan). Neurite outgrowth was evaluated under a microscope according to the following indices: index 0 : outgrowth of neurites was not encountered; index 1: a few short neurites were observed; index 2: a number of neurites were encoun-
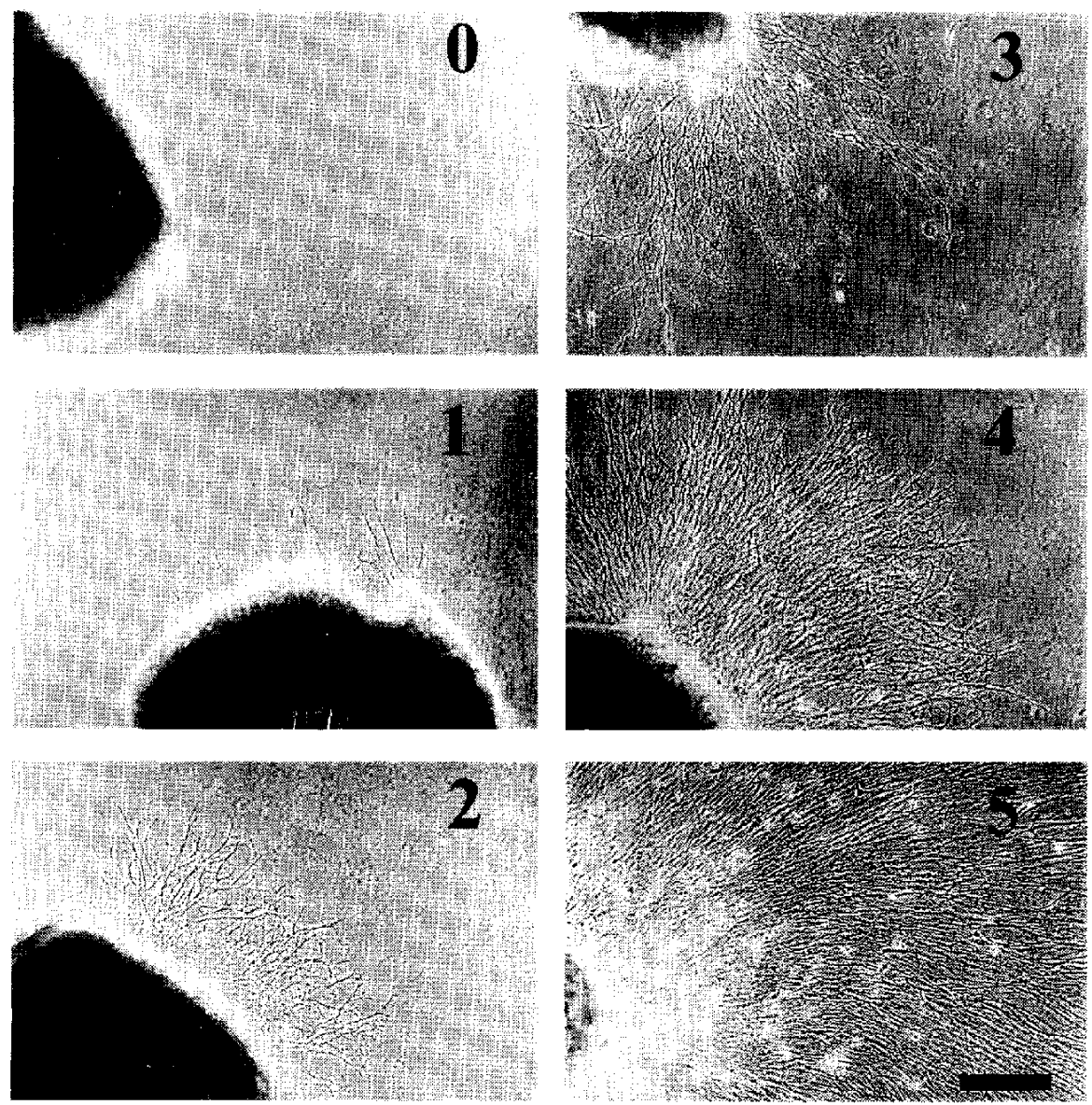

Fig. 1. Index for neurite outgrowth of cultured SCG. SCG of 3 week-old rats was cultured for 2 days with various concentrations of NGF. Neurite outgrowth was evaluated numerically by scores, index $0-5$ (see text), Bar $=240, t \mathrm{~m}$. 
tered; index 3: many neurites grew from SCG explants and some of them were elongated: index 4: numerous neurites grew; index 5 : numerous long neurites were intensely distributed. A typical figure of each index is shown in Fig. 1. The culture medium consisted of Eagle's minimum essential medium with $9.6 \%$ horse serum (M.A. Bioproducts, MD. U.S.A.), 5\% 9-day chick embryo extract, $0.46 \%$ glucose, $0.023 \%$ glutamine and $0.08 \%$ sodium bicarbonate. The NGF used in the present study was isolated from the submandibular glands of adult mice as the $2.5 \mathrm{~S}$ subunit form according to the procedure of Bocchini and Angeletti (14). The purity of the NGF was checked by polyacrylamide gel electrophoresis. Protein assay was performed by the Bradford method (15).

Short-term exposure to NGF in culture system: SCG taken from 3 week-old male rats were preincubated in the culture medium containing 1.10 or $100 \mathrm{\mu g} / \mathrm{ml} \mathrm{NGF}$ for $30 \mathrm{~min}$ at room temperature. Then they were rinsed briefly and cultured in NGF-free culture medium for 48 hours. Neurite outgrowth was evaluated as above.

Short-term exposure to NGF in transplantation system: SCG was taken from 3 weekold Wistar rats and their capsules were removed. They were cut into two pieces and preincubated with culture medium containing NGF at a concentration of $100 \mathrm{ng} .10$ or 100 $\mu \mathrm{g} / \mathrm{ml}$ for $30 \mathrm{~min}$ at room temperature. Then they were transferred into NGF-free culture medium, aspirated into the stainless-steel cannula (O.D. $=1.2 \mathrm{~mm}$ and I.D. $=0.8 \mathrm{~mm}$ ) and stereotaxically transplanted into the third ventricle of recipient rats. Fourteen days after the operation, brains were processed as above and serial $8-\mu \mathrm{m}$ paraffin sections were cut and stained with cresylviolet. Some sections were stained immunohistochemically with a monoclonal anti-tyrosine hydroxylase $(\mathrm{TH})$ antibody (kind gift of Prof. H. Hatanaka, Osaka Univ.) by an avidin-biotin peroxidase complex (Vector Laboratories, CA, U.S.A.) method (16). The number of surviving SCG neurons and graft volume was measured as described above.

Diameter of SCG neurons in grafts taken from 3 week-old rats incubated for $30 \mathrm{~min}$ in the medium containing various dosages of
NGF and then transplanted for 14 days was measured on photographs taken at random. SCGs of intact 3 week-old rats were fixed. embedded in paraffin and processed for Nissl staining. Diameter of SCG neurons in these intact controls was also measured.

Statistics: Analysis of variance (ANOVA) followed by Duncan's test was used for statistical analysis.

\section{Results}

Optimal donor age in transplantation system: Most of transplanted SCG were present in the bottom of the third ventricle of recipient rats. As shown in Fig. 2, they were well vascularized and consisted of large ganglion cell bodies. Schwann cells and/or

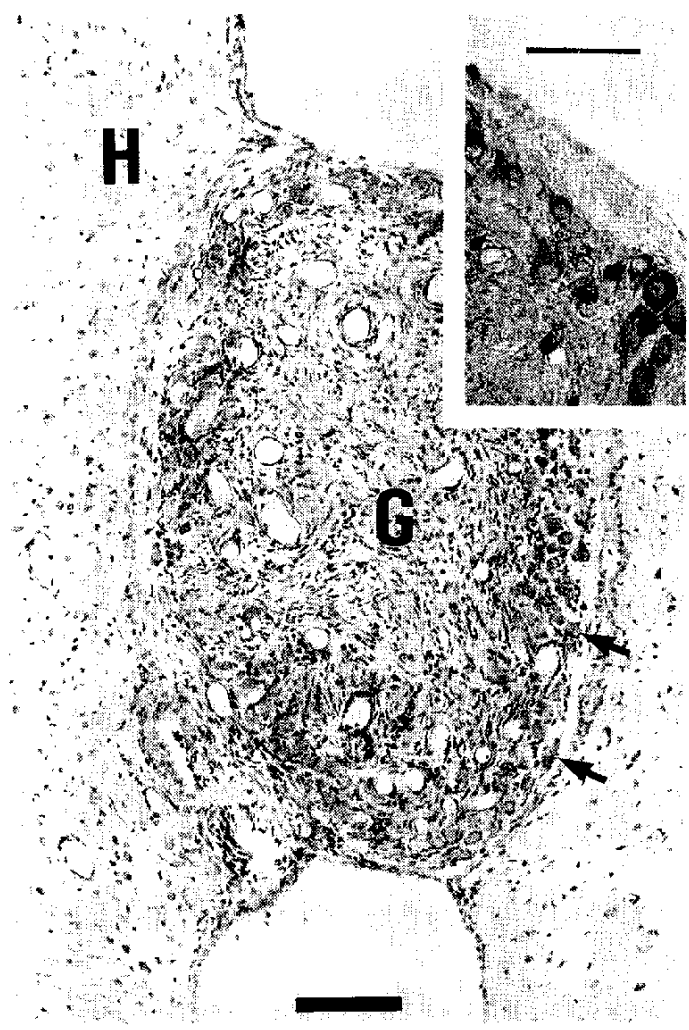

Fig. 2. A Nissl preparation of 3 week-old rat SCG transplanted into the third ventricle (III) of a male adult rat for 14 days. Large SCG neurons (arrows) are present peripherally in the graft (G). Bar $=110$ $\mu \mathrm{m}$. Insert: transplanted SCG stained immunohistochemically with anti-TH antibody. SCG neurons in the transplant are $\mathrm{TH}$-immunopositive. Bar $=100$ «m. H: hypothatamic tissue of host brain. 
Table 1. Eifect of donor age on neuronal survival of the SCG transplants

\begin{tabular}{cc}
\hline Donor age & Survival rate \\
0 day & $0 / 7$ \\
1 week & $1 / 5$ \\
2 weeks & $2 / 4$ \\
3 weeks & $5 / 7$ \\
4 weeks & $2 / 2$ \\
\hline
\end{tabular}

SCG from rats of various ages was transplanted into the third ventricle of adult rats for 14 days. Survival rate indicates the number of transplants containing surviving neurons per number of transplants performed.

fibroblasts. SCG neurons were distributed in the peripheral region of each graft. The immunohistochemical study revealed that all of the large SCG neurons were immunoreactive for TH antibody (Fig. 2, insert). SCG neurons were larger than recipient hypothalamic neurons in the adjacent area. In contrast, no surviving neurons were observed in the transplants when the tissue was taken from 0 dayold rat, although a few non-neuronal cells were rarely encountered.

A transplanted SCG tissue that contains surviving neurons was defined as a surviving graft. SCGs taken from 3 or 4 week-old rats exhibited a high survival rate (high ratio of surviving graft per total transplanted SCG) compared to other groups (Table 1). Particularly, SCG tissues derived from 3 weekold rats achieved a complete survival rate even when $30 \mathrm{~min}$ preincubation was performed before transplantation (data not shown).

Optimal donor age in terms of NGF sensitivity in culture system: Chronic NGF administration promoted neurite outgrowth in $\mathrm{O}$ dayor 3 week-old rat SCG in culture. A high outgrowth index was obtained in both the 0 dayand 3 week-old rat SCGs when they were incubated with $100 \mathrm{ng} / \mathrm{ml} \mathrm{NGF} \mathrm{(Fig.} \mathrm{3).} \mathrm{Three-}$ week old rat SCG was, however, less sensitive to NGF than those from 0 day-old rats (Figs. 3 and $4 A$ ). SCG of both groups responded to NGF in a bell-shaped manner with an optimal concentration of $10-100 \mathrm{ng} / \mathrm{ml}$. In contrast, the outgrowth of 5 week-old rat SCG treated with $100 \mathrm{ng} / \mathrm{ml} \mathrm{NGF}$ (Fig. 4B) scored less than index 1 (Fig. 3). These results indicate that the NGF sensitivity of SCG became lower with the development of SCG.

Since the SCGs of 3 week-old rats showed high sensitivity to NGF in culture (Fig. 3), and they almost always survive in transplantation

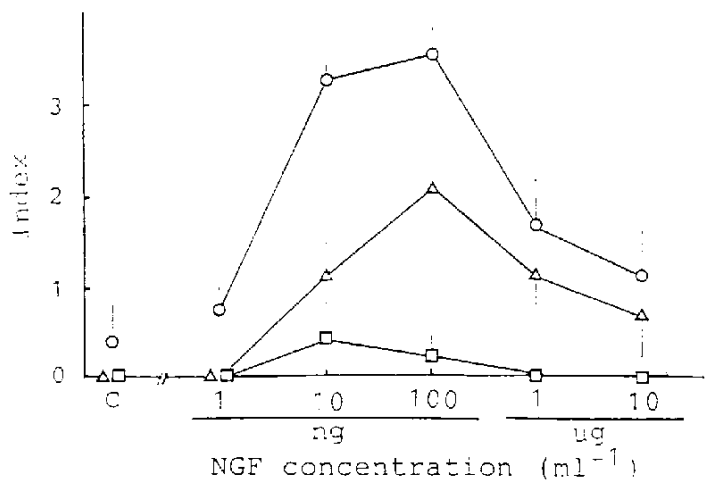

Fig. 3. Dose-response curve of neurite promoting activities of NGF in SCG of 0 day- (O), 3 week- ( $\triangle$ ) and 5 week-old rats ( $\square$ ) in tissue culture. SCG were cultured with NGF for 24 hours at the concentrations of 1,10 or $100 \mathrm{ng} / \mathrm{ml}$ or 1 or $10 \mu \mathrm{g} / \mathrm{ml}$. C SCG were cultured with NGF-free medium as controls. Mean of 6 samples \pm S.E. (vertical bars).

(Table 1), they were used for further analyses. Effect of short-term exposure to NGF in culture system: Thirty minutes exposure of SCG to NGF at the concentration of $10 \mu \mathrm{g} / \mathrm{ml}$ prior to cultivation enhanced the neurite outgrowth of SCG neurons (Fig. 5). A typical neurite outgrowth scoring index 4 is shown in Fig. 4C. The same extent of neurite outgrowth was obtained after 1 -day culture under the chronic application of $10 \mathrm{ng} / \mathrm{ml} \mathrm{NGF}$. Thus short-term application of NGF facilitated SCG neurite outgrowth in relatively higher concentration compared to chronic NGF exposure.

Effect of short-term exposure to NGF in the transplantation system: Preincubation with 10 $\mu \mathrm{g} / \mathrm{ml} \mathrm{NGF}$ for $30 \mathrm{~min}$ affected neuron survival in 3 week-old rat SCG transplanted into the third ventricle for 2 weeks. The number of SCG neurons in these grafts was 

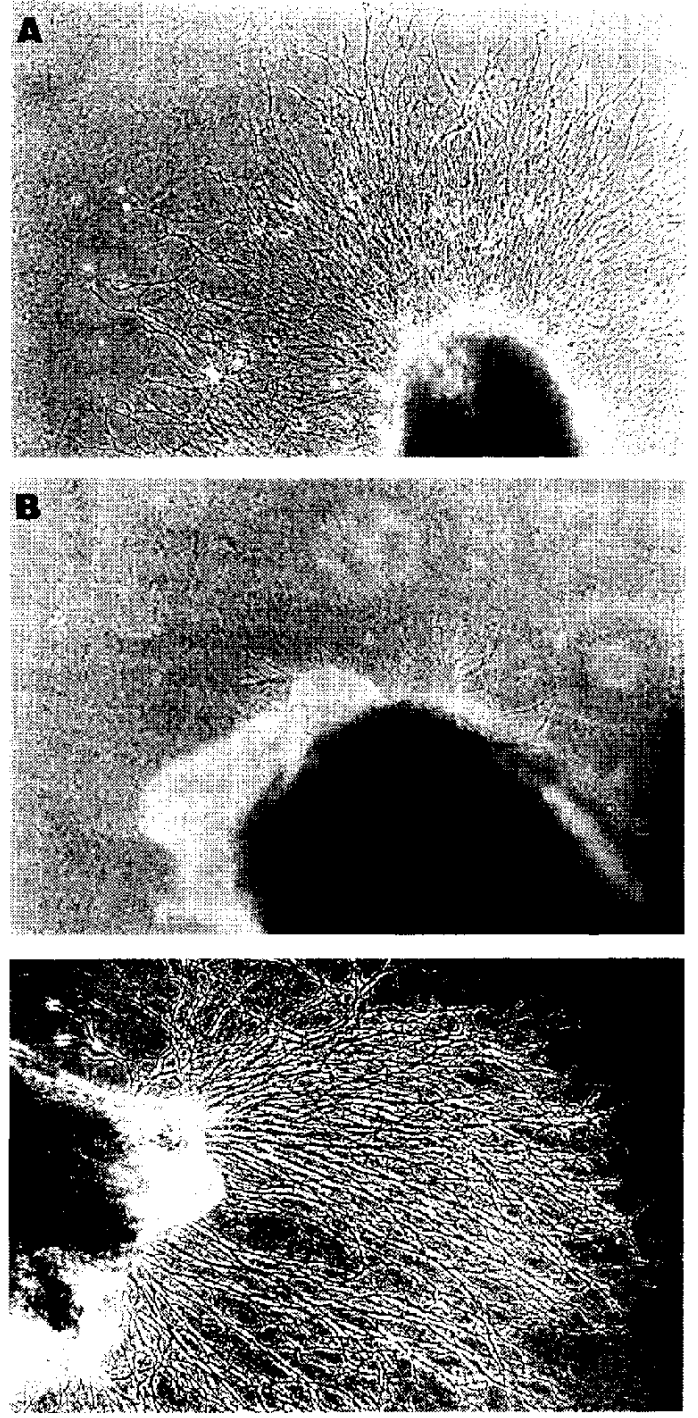

Fig. 4. Neurite outgrowth of a SCG tissue cultured with $100 \mathrm{ng} / \mathrm{ml}$ NGF for 24 hours. A SCG derived from a 3 week-o!d rat which was scored as index 4 (A) and that of a 5 week-old rat, index 1 (B). C neurite outgrowth (index 4) of a 3 week-old rat SCG cultured without NGF for 2 days after preincubation

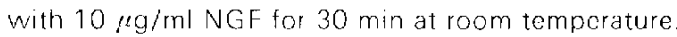

significantly greater than that of control grafts preincubated in NGF-free media before transplantation ( $P<0.05$. Fig. 6). On the other hand, the number of surviving neurons in grafts preincubated with $100 \mathrm{ng} / \mathrm{ml}$ or 100 $\mu \mathrm{g} / \mathrm{ml} \mathrm{NGF}$ remained at the control level.

The mean diameter of SCG neuronal cell bodies in NGF-free control and the 3 groups of NGF-treated transplants became significantly larger than that of the SCG neurons in 3 weekold intact rats (Table 2). This indicates that SCG neurons can maturate even after transplantation. However, NGF did not modify the neuron size.

\section{Discussion}

Limitation of the donor age available for transplantation is consistent with the previous results reported by Stenevi et al. (11). Actually, when they used newborn rats as donors, most of the SCG did not survive. Following Hendry (17), axotomy of SCG performed on 21 day-old rats resulted in only minor changes in TH and DOPA decarboxylase activities in SCG. However, axotomy before day 12 brought about a marked atrophy of SCG and noticeable reduction of enzyme content. In the present experiments, the developmental stage suitable for SCG transplantation was also older than 3 weeks. Taken together. these phenomena suggest that 3 weeks old is a critical stage of SCG development.

In the culture study, the NGF sensitivity of SCG decreased with development of SCG. This may result from the decrease of NGF re ceptor density or affinity. SCG taken from young adult rats ( 5 week-old) seemed to respond to NGF with less sensitivity. Uchida and Tomonaga reported that neurite elongation of dissociated SCG neurons of 24-30 month-old mice was enhanced to some extent by NGF when cultivated on collagen, although the NGF dependency for survival decreased in adult neurons (18). Thus, it might be considered that the NGF dependency of SCG neurons decreases with development and aging, but remains even in the SCGs of old animals. Survival of dorsal root ganglia in the presense of NGF, in contrast, is known to decrease to background levels by embryonic day 16 (19). The number of specific NGF receptors on dorsal root ganglia is known to decrease with development (20).

Short-term exposure of SCG to NGF enhanced neuron survival in transplantation. Inconsistently. Stenevi et al. (11) did not succeed in improving neuron survival of the SCG grafted into the caudal diencephalon by 


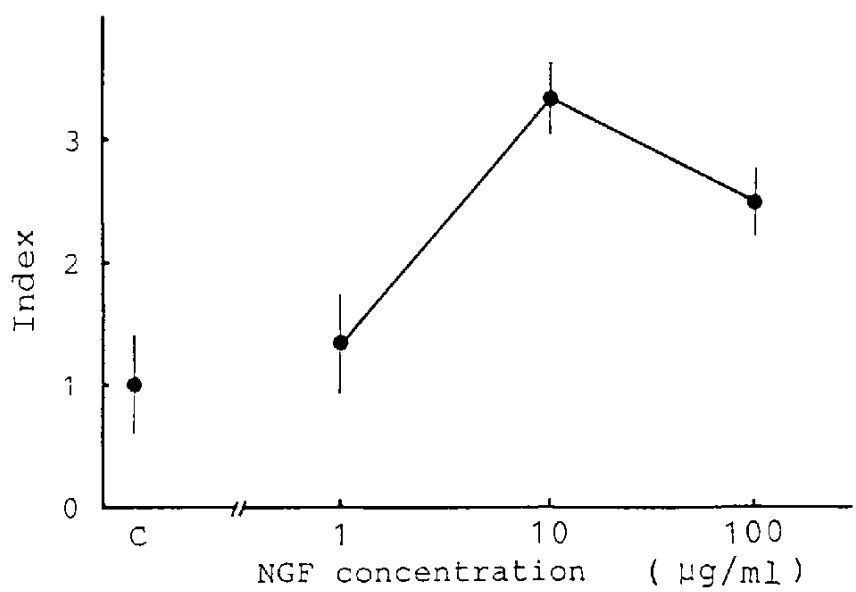

Fig. 5. Effect of short-term exposure to NGF on neurite outgrowth of SCG neurons. Three week-old rat SCG were preincubated with 1.10 or $100 \mu \mathrm{g} / \mathrm{ml} \mathrm{NGF}$ or without NGF (C) for $30 \mathrm{~min}$ at room temperature and then cultured in NGF-free culture medium for 2 days. Neurite outgrowth was evaluated according to the index shown in Fig. 1. Mean of 6 samples \pm S.E. (vertical bars).

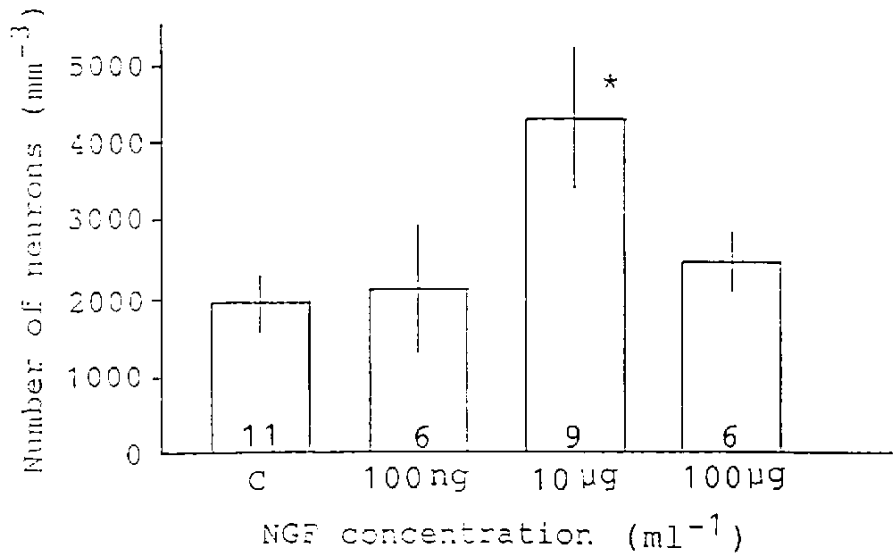

Fig. 6. Effect of short-term exposure to NGF on neuron survival in SCG transplants. Three week-old SCG were preincubated with $100 \mathrm{ng}, 10$ or $100 \mu \mathrm{g} / \mathrm{ml} \mathrm{NGF}$ then transplanted into the third ventricle. Control (C) group tissues were preincubated in NGF-free culture medium before grafting. Fourteen days later, the number of surviving neurons $/ \mathrm{mm}^{3}$ transplant was obtained. The number at the bottom of each column represents the number of animals studied. "Significant difference compared to the controls (Duncun's method, $\mathrm{P}<0.05$ ).

Table 2. Effect of NGF on size of transplanted SCG neurons

\begin{tabular}{cc}
\hline Group & Mean \pm S.E. \\
\hline Intact control & $14.90 \pm 0.40(20)$ \\
Graft control & $20.54 \pm 0.75(24)^{* *}$ \\
NGF $100 \mathrm{ng} / \mathrm{ml}$ & $18.91 \pm 0.63(16)^{* *}$ \\
$10 \mu \mathrm{g} / \mathrm{ml}$ & $19.51 \pm 0.63(24)^{* *}$ \\
$100 \mu \mathrm{g} / \mathrm{ml}$ & $19.43 \pm 0.71(16)^{* *}$ \\
\hline
\end{tabular}

Diameter of transplanted SCG neurons, which were treated with NGF or without NGF (Graft control) before grafting, and that of SCG neurons in 3 week-old rats (Intact cantrol) were measured on photographs. "*ignificant difference compared to the intact control (Duncun's method, $\mathrm{P}<0.01$ ). 
short-term NGF exposure. Two explanations are possible for their negative results: the location of the transplants and the NGF dosage. They transplanted SCG into brain parenchyme, caudal diencephalon. whereas we employed the third ventricle as the site of grafting. Ventricles are supposed to function as an in situ culture chamber. promoting better neuron survival than parenchyme. The NGF concentration that enhanced the survival of transplanted neurons $(10 \mu \mathrm{g} / \mathrm{ml})$ was higher than that in their study $(100 \mathrm{BU} / \mathrm{ml}$, i.e., about $1 \mu \mathrm{g} / \mathrm{ml}$ ). The present study ascertained that a low concentration of NGF was not effective in short-term application prior to both transplantation and culture and that a high concentration $(100 \mu \mathrm{g} / \mathrm{ml})$ of NGF also did not significantly affect the number of surviving neurons in grafts. Therefore, there might be an optimal NGF concentration for enhancing the neuron survival in short-term exposure. Moreover, the present culture study revealed that the optimal dosage of NGF in short-term treatment was one hundred times greater than that in chronic application.

Since most of the SCG neurons grafted into the brain died during the first 24 hours after transplantation (21), the promotion of survival during this period may be an important factor for the success of transplantation. Short-term NGF exposure was ascertained to be effective during this period, at least in culture. It is possible that the pretreatment with NGF enhanced neuron survival in the initial step of transplantation. NGF is generally supposed to interact with its specific receptors located on the surface of neurons, but there is no solid information on the intracellular mechanisms of NGF action. Since short-term NGF treatment induced long-lasting effects, it might be considered that NGF uptaken during preincubation played a role in triggering subsequent events in SCG neurons, enhancing survival in the ectopic host ventricle.

Transplanted SCG neurons grew in size even in the third ventricle, suggesting that the grafted tissue received trophic support from the host brain through blood circulation. NGF was ineffective on this neuron maturation. NGF, indeed, did not induce any obvious alterations in the vasculature of the grafted
SCG.

Acknowledgment: We thank Dr. Nobuyoshi Nishiyama for his critical reading of this manuscript.

\section{References}

1 Gage, F.H.: Grafts of fetal septal cholinergic neurons to the hippocampal formation in aged or fimbria-fornix-lesioned rats. Ann. N.Y. Acad. Sci. 595, 120-137 (1987)

2 Olson, L., Stromberg, I., Herrera-Marschnitz, M., Ungerstedt, $V$. and Ebendal, T.: Adrenomedullary tissue grafted to the dopamine denervated rat striatum: Histochemical and functional effects of additions of NGF. In Neural Grafting in the Mammalian CNS, Edited by Bjorklund. A. and Stenevi, U., p. 505-518, Elsevier, Amsterdam (1985)

3 Backlund, E.O., Granberg, P.O., Hamberger, B., Knutsson, E., Martensson, A.r Sedvali, G., Seiger, A. and Olson, L.: Transplantation of adrenal medullary tissue to striatum in parkinsonism. J. Neurosurg. 62, 169-173 (1985)

4 Madrazo, I., Drucker-Colin, R., Diaz, V. and Martinez-Mata, J.: Open microsurgical autograft of adrenal medulla to the right caudate nucleus in two patients with intractable parkinson's disease. N. Engl. J. Med. 316, 831-834 (1987)

5 Madrazo, I., Leon, V., Torres, C., Aguilera M.C., Varela, G., Alvarez, F. and Fraga, A.: Transplantation of fetal substantia nigra and adrenal medulla to the caudate nucleus in two patients with parkinsons disease. N. Engl. J. Med. 318, 51 (1981)

6 Thoenen, $H$. and Barde, Y.A.: Physiology of nerve growth factor. Physiol. Rev. 60, 12841335 (1980)

7 Hatanaka, H. and Tsukui, H.: Differential effect of nerve-growth factor and glioma-conditioned medium on neurons cultured from various regions of fetal rat central nervous system. Dev. Brain Res. 30, 47-56 (1986)

8 Hefti, F.: Nerve growth factor promotes survivals of septal cholinergic neurons after fimbrial transections. J. Neurosci. 6, 2155-2162 (1986)

9 Williams, L.R., Varon, S., Peterson, G.M., Wictorin, K., Fischer, W., Bjorklund, A. and Gage, F.H.: Continuous infusion of nerve growth factor prevents basal forebrain neuronal death after fimbria fornix transection. Proc. Natl. Acad. Sci. U.S.A. 83, 9231-9235 (1986)

10 Kromer, L.F.: Nerve growth factor treatment after brain injury prevents neuronal death. Science 235, 214-216 (1987)

11 Stenevi, U., Björklund, A. and Svendgaard, 
N.A.: Transplantation of central and peripheral monoamire neurons to the adult rat brain: Techniques and conditions for survival. Brain Res. 114, 1-20 (1976)

12 Paxinos, G. and Watson, C.: The Rat Brain in Stereotaxic Coordinates. Academic Press. New York (1982)

13 Konigsmark, B.W.: Methods for the counting of neurons. In Contemporary Research Methods in Neuroanatomy, Edited by Nauta, W.J.H. and Ebbesson, S.O.E., p. 315-340, Springer-Verlag. Berlin. Heiderberg. New York and Tokyo (1970)

14 Bocchini, $V$. and Angeletti, P.U.: The nerve growth factor: purification as a 30.000 molecular-weight protein. Proc. Nat!. Acad. Sci. U.S.A. 64, 787-794 (1969)

15 Bradford, M.M.: A rapid and sensitive method for the quantitation of microgram quantities of protein utilizing the principle of protein-dye binding. Anal. Biochem. 72, 248-254 (1976)

16 Su-Ming Hsu, Raine, L. and Fanger, $\mathrm{H}$.: Use of avidin-biotin-peroxidase complex (ABC) in immunoperoxidase techniques: A comparison between $\mathrm{ABC}$ and unlabeled antibody (PAP) procedures, J. Histochem. Cytochem. 29, $577-$ $580(1981)$

17 Hendry, I.A.: The effects of axotomy on the development of the rat superior cervical ganglion. Brain Res. 90, 235-244 (1975)

18 Uchida, $Y$. and Tomonaga, M.: Effects of nerve growth factor and heart cell conditioned medium on neurite regeneration of aged sympathetic neurons in culture. Brain Res. 348, 100-106 (1985)

19 Barde, Y.A., Edgar, D. and Thoenen, H.: Sensory neurons in culture: Changing requirements for survival factors during embryonic development. Proc. Natl. Acad. Sci. U.S.A. 77, 1199-1203 (1980)

20 Herrup, K. and Shooter, E.M.: Properties of the $\beta$-nerve growth factor receptor in development. J. Cell Biol. 67, 118-125 (1975)

21 Zhou, C.F., Lindsay, R.M., Lawrence, J.M. and Raisman, G.: Extent of survival and vascularization of adult superior cervical sympathetic or nodose ganglia transplanted into the septal nuclei or choroid fissure of adult rats. Neuroscience 17, 803-813 (1986) 